\title{
Proceeding
}

Supplementary Issue: Winter Conferences of Sports Science. Costa Blanca Sports Science Events, 22-23 March 2021. Alicante, Spain.

\section{The neuropsychological effects of motor development mediated by technologies in disabled subjects}

\author{
FEDERICA DORONZO , PIERGIORGIO GUARINI \\ Department of Humanistic Studies, University of Foggia, Italy
}

\begin{abstract}
Background: the sector of motor development mediated by technologies in disabled subjects is growing. It is becoming popular as subject of interdisciplinary studies in engineering, neuroscientific, psychological and pedagogical fields. Nevertheless, only in the last few years scientific studies in motor development mediated by technologies in disabled subjects are analysing and studying the neuropsychological effects of such practices as well. Objective: the purpose of this work is the analysis of the scientific literature about the effects of the employment of technologies in motor abilitation/rehabilitation in disabled subjects. It will identify and track the research paths that scientific studies are following. The identification will be based on the scientific production of the last decade. The target includes adults and children. Material and methods: this work started researching combined words among the concepts of motor development, technology, disability and effects in electronic databases. In order to be considered valuable, the studies must have the purpose to measure the motivational, emotional and/or cognitive effects associated with motor development. Scientific papers which don't focus mainly on psychological implication were excluded from this review. Results: this work observes that international scientific literature strongly focused on 4 macro-categories, related to the technology used: 1) assistive robots, 2) brain-computer interface (BCI); 3) augmented or virtual reality; (3) technology-aided support tools and interactive apps. These tools produce a recovery or improvement in different fields: motor, social, cognitive, emotional and motivational. Conclusions: the research about motor development mediated by technologies in disabled subjects has a wide reach in the recovery of neuromotor deficit and in the acquisition or improvement of neuropsychological competences. The effects can generate relapses not only in the field of neuro-motricity but also in educational and mental health field.
\end{abstract}

Keywords: Motor development; Disability; Emotion; Cognition; Motivation; Technology.

Cite this article as:

Doronzo, F., \& Guarini, P. (2021). The neuropsychological effects of motor development mediated by technologies in disabled subjects. Journal of Human Sport and Exercise, 16(3proc), S963-S972. https://doi.org/10.14198/ihse.2021.16.Proc3.12

Corresponding author. Department of Humanistic Studies, University of Foggia, Italy.

E-mail: gyv.toto@gmail.com

Abstract submitted to: Winter Conferences of Sports Science. Costa Blanca Sports Science Events, 22-23 March 2021. Alicante, Spain.

JOURNAL OF HUMAN SPORT \& EXERCISE ISSN 1988-5202.

(c) Faculty of Education. University of Alicante.

doi:10.14198/jhse.2021.16.Proc3.12 


\section{INTRODUCTION}

People affected by motor disability experience several challenges and disadvantages in their everyday activities, not only in motor efforts but also in cognition, emotional and motivational fields. The concept of embodiment proves the existence of a unity among mind, body and environment: the corporeality allows the existence of the being related to the Self and to the Other (Gatta and Salerno, 2018; Limone \& Toto, 2018).

The neuromotor rehabilitation technology has developed in the last decade, getting into clinical contests. It was able to cause improvement in gait, posture, balance and functionality of the limbs. The rehabilitation planning was also able to evolve along with more intense treatments, increasingly motivating and stimulating environments, customized protocols, objective measurements of the answers and the improving of rehabilitation projects effectiveness.

Yazıcı, M. et al have proved in 2019 that robotic motor rehabilitation causes a faster and more relevant effect on motor development in children with hemiparetic cerebral palsy than standard physiotherapy.

There are several methodologies adopted in order to help motor development, nevertheless it is possible to divide them in four macro categories: 1) assistive robots, 2) brain-computer interfaces (BCl), 3) virtual or augmented realities, 4) technology-aided support tools and interactive apps.

Neuroscience has corroborated the thesis according to which motor neurocircuits are linked to cognitive, emotional and motivational functions.

Yamauchi et al. research in 2019 suggested that the achievement of walking could facilitate the cognitive/linguistic development in children with Down syndrome; data from Geertsen et al. (2016) also demonstrate that motor capabilities are positively linked with cognitive functions and academic performances in pre-teen children.

The relation between movement and emotions is instead supported by the existence of common cerebral areas involved in emotions and movement. In Moseley et al. (2015) they hypothesize that the under activation of the motor and limbic regions which elaborate emotional texts can be the reason for emotional language difficulties in the autistic spectrum. Furthermore, by studying some pathologies (such as Huntington's disease), it has been proved that basal ganglia (Florio et al., 2018) and the cerebellum (Schmahmann et al., 2019) adjust both motor capabilities and affectivity.

Moreover, the association between motor function and motivation has been proved thanks to the work of Felger et al. (2017): they demonstrated that motivational and motor functions deficit are associated with alterations of the same neurocircuit, the corticostriatal.

The reached cognitive goals open to a brand new question: does there exist a positive correlation between disabled people's motor development and improvement of cognition, motivation and emotion? Can the motor training be the mediator of a multi-domain improvement? 


\section{MATERIALS AND METHODS}

In order to accomplish the goal of the paper, it has been used a Rapid Evidence Assessment (REA) instead of a complete, systematic review. This choice was determined by the need to produce a sudden response and by the shortage of available scientific production about the object of study.

The REA was born from the need to produce timely reviews in order to make decisions about cures and medical treatments (Varker et al., 2015). The rapidity of the REA is an advantage for knowledge and for the questions which need fast answers.

Although it is a tool used for lack of time, it does not imply that the rigor in identifying, evaluating and summarizing or the details of the work selected are of lower quality than a systematic review.

It is conceivable that the reduced time for the research could an effective availability and could lead the researchers to run into publication bias (Jolliffe et al., 2007), which occurs when the outcome of an experiment or research study influences the decision whether to publish or otherwise distribute it: research with significant findings have more probabilities to be published rather than research with null findings.

\section{Inclusion and exclusion criteria}

The REA has been conducted on studies published in English. The purpose was to identify the works which experimented the effects of motor development in cognitive, emotional and motivational fields, mediated by technologies in disabled people.

All the selected abstracts, following the question of the REA, have been subject of discussion, although some of those papers were not fully accessible.

Studies without implications on cognitive, emotional and motivational effects in response to motor development were excluded.

\section{Research strategy}

The research has used combined terms for every principal concept of motor development, disability, technology, motivation, cognition, emotion. It took into account only studies published between 2010 to 2020, searching the electronic databases of Scopus, Web of Science and PubMed.

Each reference has been evaluated for potential relevance and then the research has applied the inclusion criteria. The research has identified for macro-categories: 1) assistive robots, 2) brain-computer interfaces $(\mathrm{BCl}), 3)$ virtual or augmented reality and 4) technology-aided support tools and interactive apps.

\section{RESULTS}

The research has identified 246 papers, which became 24 after the exclusion following the chosen criterion. After deepening those 24 papers, other 12 were excluded, because they focused on the rehabilitation of motor functions, cognitive, motivational and emotional at the same time, or because they focused only on motor therapy without a contemporary psychological deepening. From the 12 papers left after the application of the exclusion criteria, for 7 of these only the abstract was available. 
Table 1 represents the classification of the four macro-categories emerged from the REA procedure. The four categories are: 1) assistive robots, 2) brain-computer interfaces (BCl), 3) virtual or augmented realities, 4) technology-aided support tools and interactive apps.

Table 1. Macro-categories of the applied technologies.

\begin{tabular}{|c|c|c|c|c|}
\hline Paper & $\begin{array}{l}\mathrm{BCl} \text { (computer- } \\
\text { brain interface) }\end{array}$ & $\begin{array}{l}\text { Augmented or } \\
\text { virtual reality }\end{array}$ & $\begin{array}{l}\text { Assistive } \\
\text { robots }\end{array}$ & $\begin{array}{l}\text { Technology-aided support } \\
\text { tools and interactive app }\end{array}$ \\
\hline $\begin{array}{l}\text { Rogers, J.M., et } \\
\text { al. (2019) }\end{array}$ & & $\mathrm{x}$ & & \\
\hline $\begin{array}{l}\text { Buitrago, J. A., } \\
\text { et al. (2020) }\end{array}$ & & & $\mathrm{x}$ & \\
\hline $\begin{array}{l}\text { Kokkoni, E., et } \\
\text { al. (2020) }\end{array}$ & & & $\mathrm{x}$ & $\mathrm{x}$ \\
\hline $\begin{array}{l}\text { Cappagli, G., et } \\
\text { al. (2019) }\end{array}$ & & & & $\mathrm{x}$ \\
\hline $\begin{array}{l}\text { Lancioni, G. E., } \\
\text { et al. (2019) }\end{array}$ & & & & $\mathrm{x}$ \\
\hline $\begin{array}{l}\text { Pulay, M. Á. } \\
\text { (2015) }\end{array}$ & & $\mathrm{x}$ & & \\
\hline $\begin{array}{l}\text { Taherian, S., et } \\
\text { al. (2016) }\end{array}$ & $\mathrm{x}$ & & & \\
\hline $\begin{array}{l}\text { Coutinho, F., et } \\
\text { al. (2017) }\end{array}$ & & & & $x$ \\
\hline $\begin{array}{l}\text { Cook, A., et al. } \\
\text { (2010) }\end{array}$ & & & $\mathrm{x}$ & \\
\hline $\begin{array}{l}\text { Cook, A. M., et } \\
\text { al. (2012) }\end{array}$ & & & $\mathrm{x}$ & \\
\hline Wei, W. (2018) & $x$ & $x$ & & \\
\hline $\begin{array}{l}\text { Burridge, J.H., } \\
\text { et al. (2017) }\end{array}$ & & & & $\mathrm{x}$ \\
\hline
\end{tabular}

We will now explore the experimented technologies in the selected papers.

The Elements adopt virtual reality to improve neuroplastic recovery in stroke patients. It aims to the creation of an enriched environment which should solicit the patient to interact with a display through motor activation; it provides constant informative feedbacks about the performance and it adapts itself to the patient's capacities and needs. Improvements at motor level have been evaluated through the Box and Blocks Task (BBT), and cognitive level with several tests, such as the Montreal cognitive assessment (MOCA). In the experimental group the motor and cognitive recovery is transferred to everyday life and it is two or three times higher than the recovery of the control group, which has been treated with a conventional physiotherapy therapy (Roges et al., 2019).

La Grounded Early Adaptive Rehabilitation (GEAR) is a cyber-physical system, implemented as a technological playground, made by: a body weight support (BWS) tool, assistive robots and data collection and management software. The enriched hybrid environment allows the perceptive, cognitive, linguistic, motor and cognitive development in children. The projected space is addressed to children with mobility problems or delays in development. 
Kokkoni et al in 2020 tested the systems with a Down syndrome 24 months old subject. Collected data showed the protocol potentiality in motor, cognitive and social rehabilitation.

Audio Bracelet for Blind Interaction (ABBI) is a wearable technology with audio system, motion sensor and Bluetooth to connect with a smartphone. The bracelet produces an auditory feedback monitoring body movement, to build motor skills. The patients were visually impaired children aged between 6 and 17 years, who have acquired improved consciousness of body-space, improving spatial mobility and cognition (Cappagli et al., 2019).

Technology-Aided Programs are tools to support people with significant disabilities, such as motor disabilities, so that they can build a satisfactional interaction with the environment. This way promotes general results, such as increasing life quality, social and cognitive capabilities (Lencioni et al., 2019; Toto \& Limone, 2021). Lancioni et al. 2019 work focused on patients forced in a wheelchair by motor disabilities. The group installed the MacroDroid app on their smartphones, which works as a stimulation tool and sensor for a technological device installed on their wheelchairs. The app can monitor and promote two motor functional responses. Using this tool induced higher motor responses and indices of happiness in the participants of the experiment.

LifeCIT is a support program for stroke patients who use Constraint Induced Therapy (CIT) at home. The increase in motivation was detected but is dependent to the presence of the therapist during the distance treatment. One of the tools adopted is the C-Mitt (glove with sensors) which is able to detect upper limb movement data and send them to the operator remotely connected (Burridge et al., 2017).

Brain-computer interface $(\mathrm{BCl})$ is a recent technology with great rehabilitative potential. Using the motor $\mathrm{BCl}$, electronic registration of motor cortex in paralysed subjects are decoded by a computer and used to guide robotic limbs or to restore the movement of a paralyzed hand stimulating muscles (Rosenfeld et al, 2017).

It has been noticed a positive effect from the Human Body Posturizer (HBP), a rehabilitative exoskeleton, in mood modulation in institutionalized elderly subjects (Verrusio et al., 2018).

A similar result emerged from McGibbon et al, in 2021, a study on the effects of an exoskeleton in multiple sclerosis subjects: they observed an emotional wellness increase besides benefits in physical functioning.

Table 2. Effects of motor development.

\begin{tabular}{lccc}
\hline Article & Cognitive effect & Motivational effects & Emotional effects \\
\hline Rogers, J.M., et al. (2019) & $\mathrm{x}$ & $\mathrm{x}$ \\
Buitrago, J. A., et al. (2020) & $\mathrm{x}$ & \\
Kokkoni, E., et al. (2020) & $\mathrm{x}$ & $\mathrm{x}$ \\
Cappagli, G., et al. (2019) & & \\
Lancioni, G. E., et al. (2019) & $\mathrm{x}$ & $\mathrm{x}$ \\
Pulay, M. Á. (2015) & & $\mathrm{x}$ \\
Taherian, S., et al. (2016) & $\mathrm{X}$ & $\mathrm{x}$ \\
Coutinho, F., et al. (2017) & $\mathrm{x}$ & \\
Cook, A., et al. (2010) & $\mathrm{x}$ & $\mathrm{x}$ \\
Cook, A. M., et al. (2012) & & $\mathrm{x}$ \\
Wei, W. (2018) & & \\
Burridge, J.H., et al. (2017) & & \\
\hline
\end{tabular}


Table 2 represents psychological effects associated with motor development.

Table 2 shows that the most studied and detected effects are cognitive and motivational, mostly associated with improvement of lifestyle and adherence to treatment. In the research emotional effects emerged only in Lancioni et al.'s paper.

We may suppose that emotional effects are more present but not studied. This trend could be linked to the complexity of evaluation of patients' emotional states and difficulty of the latter to be aware and to verbalize their emotions. Nevertheless, scientific literature has proved the connection between physical activity and increased mood. Mikkelsen et al., in 2007 confirmed the positive effects of physical activity on anxiety, stress and depression.

These results are attributable to the correlation between physical activity and increase in synthesis and release both of neurotransmitters and neurotrophic factors. These increases can be associated with neurogenesis, angiogenesis and neuroplasticity, which are fundamental processes to treat psychiatric pathologies, neurodegenerative diseases and acquired or congenital disabilities. Table 3 is an overview about the content of the selected papers.

Table 3. Overview of reviewed studies.

\begin{tabular}{|c|c|c|}
\hline Authors & Type & Summary and key points \\
\hline $\begin{array}{l}\text { Rogers, } \\
\text { J.M., et } \\
\text { al. (2019) }\end{array}$ & $\begin{array}{l}\text { Randomized } \\
\text { controlled trial }\end{array}$ & $\begin{array}{l}\text { The Elements system uses virtual reality to rehabilitate upper limbs in } \\
\text { stroke patients. This integration of this training with a conventional } \\
\text { physiotherapy treatment produced a motor and cognitive recovery } \\
\text { significantly greater than the control group one. }\end{array}$ \\
\hline $\begin{array}{l}\text { Buitrago, } \\
\text { J.A., et } \\
\text { al. }(2020)\end{array}$ & Case report & $\begin{array}{l}\text { The social care robot } \mathrm{NAO} \text { supports a physiotherapy program addressed } \\
\text { to children with cerebral paresis. It has been observed facilitation in } \\
\text { walking, participation and motivation. }\end{array}$ \\
\hline $\begin{array}{l}\text { Kokkoni, } \\
\text { E., et al. } \\
(2020)\end{array}$ & $\begin{array}{l}\text { Methodological } \\
\text { paper }\end{array}$ & $\begin{array}{l}\text { The GEAR system is a hybrid paediatric learning environment meant for } \\
\text { motor development through robot-child social interaction. Preliminary } \\
\text { results support its potential to improve motor, cognitive and social } \\
\text { systems. }\end{array}$ \\
\hline $\begin{array}{l}\text { Cappagli, } \\
\text { G., et al. } \\
(2019)\end{array}$ & Clinical trial & $\begin{array}{l}\text { ABBI training protocol is centred on motor-audio associations in order to } \\
\text { induce an improvement of spatial capacities in visually impaired children. } \\
\text { The observed strengthening is related both to mobility and to spatial } \\
\text { cognition. }\end{array}$ \\
\hline $\begin{array}{l}\text { Lancioni, } \\
\text { G., et al. } \\
(2019)\end{array}$ & Review & $\begin{array}{l}\text { The microswitches linked to computer systems promote the development } \\
\text { of body functional movement in subjects with intellectual and motor } \\
\text { disabilities. } \\
\text { An observed effect is motivational and communication improvement. }\end{array}$ \\
\hline $\begin{array}{l}\text { Pulay, } \\
\text { M.A. } \\
\text { (2015) }\end{array}$ & Review & $\begin{array}{l}\text { Augmented reality allows to develop relevant motor experiences in } \\
\text { children with great physical disabilities. The motor experiences in turn } \\
\text { promote cognition. However, this review also detects cognitive } \\
\text { dysfunction cases. }\end{array}$ \\
\hline $\begin{array}{l}\text { Taherian, } \\
\text { S., et al. } \\
(2016)\end{array}$ & Case report & $\begin{array}{l}\text { A patient with tetraplegic spastic cerebral palsy was trained to use } \mathrm{BCl} \\
\text { based on EEG through a game which involved upper limbs. The learning } \\
\text { produced an improvement of communicative capacities mediated by an } \\
\text { app and a motivation increase. }\end{array}$ \\
\hline
\end{tabular}




\begin{tabular}{|c|c|c|}
\hline $\begin{array}{l}\text { Coutinho } \\
\text { F., et al. } \\
(2017) \\
\text { Cook A., } \\
\text { et al. } \\
(2010)\end{array}$ & $\begin{array}{l}\text { indomized } \\
\text { ntrolled trial }\end{array}$ & $\begin{array}{l}\text { e use of iPad apps to develop visual-motor skills in rehabilitation for } \\
\text { ildren aged between } 4 \text { and } 7 \text { years with special needs is associated } \\
\text { th an increase of motivation and interest in therapy. } \\
\text { ing robots to assist in game and academic activities children with motor } \\
\text { abilities has a direct impact on the development of their cognitive, } \\
\text { cial and linguistic abilities. }\end{array}$ \\
\hline $\begin{array}{l}\text { Cook A. } \\
\text { et al., } \\
\text { (2012) }\end{array}$ & view & $\begin{array}{l}\text { sistive robots mediate an augmented manipulation and communication } \\
\text { children affected by motor disabilities. Using this technology allows } \\
\text { Idren to independently explore and interact with the environment, also } \\
\text { termining the development of cognitive capacities. }\end{array}$ \\
\hline $\begin{array}{l}\text { Wei W. } \\
\text { (2018) }\end{array}$ & ok & $\begin{array}{l}\text { in function of the robotic exoskeleton in stroke patients } \\
\text { ms to the restoration of upper limb motor function. The } \\
\text { ct can potentially motivate the subjects to execute } \\
\text { i times. }\end{array}$ \\
\hline $\begin{array}{l}\text { Burridge } \\
\text { JH et al } \\
\text { (2017) }\end{array}$ & le & $\begin{array}{l}\text { The innovative model of telemedicine has generated the implementation } \\
\text { of LifeCIT program. The use of wearable sensors which monitor } \\
\text { movement in stroke patients can increase motivation and adherence to } \\
\text { rehabilitation programs. }\end{array}$ \\
\hline
\end{tabular}

\section{CONCLUSIONS}

This research focused on the 2010 decade, however the majority of papers selected were written in a recent and short period of time. Studies related to neuropsychological effects in motor development seem innovative compared to the previous literature.

It has been proved that motor rehabilitation/qualification induce recovery or acquisition of different capacities compared to the ones in the treated target. Cognitive and motivational domains are particularly studied and their improvement is evident in neuro motricity centred therapies mediated by technologies. The emotional sphere also seems relevant, but there is few evidence.

Cognitive, motivational and emotional effects emerge with more evidence in protocols mediated by technologies rather than conventional treatments. In the perspective of future research, it is also essential to deepen the relationship between subjects and machines, especially in terms of resistance and acceptance (Toto \& Limone 2020; 2021).

Being aware about the correlation between these effects and the motor system means taking charge of the patient in an effective and complete way, ensuring a better standard of living.

Future research are needed to further support the effectiveness of motor rehabilitation on improving cognitive, emotional and motivational functions. There is a need to validate the use of specific technologies and their effects, improve knowledge of therapeutic processes, collect further evidence on outcomes on other domains and formulate personalized goals and sessions.

We would like larger and more controlled studies to identify the characteristics of subjects who have the best chance of benefiting from the use of new technologies and specific guidelines on how to use them. 


\section{REFERENCES}

Buitrago, J. A., Bolaños, A. M., \& Caicedo Bravo, E. (2020). A motor learning therapeutic intervention for a child with cerebral palsy through a social assistive robot. Disability and rehabilitation. Assistive technology, 15(3), 357-362. https://doi.org/10.1080/17483107.2019.1578999

Burridge, JH, Lee, ACW, Turk, R., Stokes, M., Whitall, J., Vaidyanathan, R., ... e Yardley, L. (2017). Telehealth, Wearable Sensors, and the Internet: Will They Improve Stroke Outcomes Through Increased Intensity of Therapy, Motivation, and Adherence to Rehabilitation Programs? Journal of Neurologic Physical Therapy, 41, S32-S38. https://doi.org/10.1097/NPT.0000000000000183

Cappagli, G., Finocchietti, S., Cocchi, E., Giammari, G., Zumiani, R., Cuppone, A. V., Baud-Bovy, G., \& Gori, M. (2019). Audio motor training improves mobility and spatial cognition in visually impaired children. Scientific reports, 9(1), 3303. https://doi.org/10.1038/s41598-019-39981-x

Cook, A. M., Adams, K., Encarnação, P., \& Alvarez, L. (2012). The role of assisted manipulation in cognitive development. Developmental Neurorehabilitation, 15(2), 136-148. https://doi.org/10.3109/17518423.2011.635609

Cook, A., Encarnaço, P., \& Adams, K. (2010). Robots: Assistive technologies for play, learning and cognitive development. Technology and Disability, 22(3), 127-145. https://doi.org/10.3233/TAD$\underline{2010-0297}$

Coutinho, F., Bosisio, M. E., Brown, E., Rishikof, S., Skaf, E., Zhang, X., Perlman, C., Kelly, S., Freedin, E., \& Dahan-Oliel, N. (2017). Effectiveness of iPad apps on visual-motor skills among children with special needs between 4y0m-7y11m. Disability and rehabilitation. Assistive technology, 12(4), 402410. https://doi.org/10.1080/17483107.2016.1185648

Della Gatta F. and Salerno G., (2018). La mente dal corpo: I'embodiment tra fenomenologia e neuroscienze. Ineditedizioni.

Felger, J., Treadway, M. (2017). Inflammation Effects on Motivation and Motor Activity: Role of Dopamine. Neuropsychopharmacol 42, 216-241. https://doi.org/10.1038/npp.2016.143

Florio TM, Scarnati E, Rosa I, Di Censo D, Ranieri B, Cimini A, Galante A, Alecci M. (2018) The Basal Ganglia: More than just a switching device. CNS Neurosci Ther. https://doi.org/10.1111/cns.12987

Jolliffe, D., \& Farrington, D. P. (2007). A rapid evidence assessment of the impact of mentoring on reoffending: A summary. London: Home Office.

Kokkoni, E., Mavroudi, E., Zehfroosh, A. et al. (2020). GEARing smart environments for pediatric motor rehabilitation. J NeuroEngineering Rehabil 17, 16. https://doi.org/10.1186/s12984-020-0647-0

Korup, V., Nielsen, C. M., Wienecke, J., Ritz, C., Krustrup, P., \& Lundbye-Jensen, J. (2016). Motor Skills and Exercise Capacity Are Associated with Objective Measures of Cognitive Functions and Academic Performance in Preadolescent Children. PloS one.

Lancioni, G. E., Singh, N. N., O'Reilly, M. F., Sigafoos, J., Campodonico, F., \& Alberti, G. (2017). Use of a Smartphone for Leisure and Communication by People with Blindness and Motor Disabilities. Journal of Visual Impairment \& Blindness, 111(2), 181-186. https://doi.org/10.1177/0145482X1711100211

Lancioni, G. E., Olivetti Belardinelli, M., Singh, N. N., O'Reilly, M. F., Sigafoos, J., \& Alberti, G. (2019). Recent Technology-Aided Programs to Support Adaptive Responses, Functional Activities, and Leisure and Communication in People With Significant Disabilities. Frontiers in neurology, 10, 643. https://doi.org/10.3389/fneur.2019.00643

Limone, P. \& Toto G. (2018). The psychological constructs and dimensions applied to sports performance: a change of theoretical paradigms. Journal of Physical Education and Sport, 18, 2034.

Limone, P. (2021, January). Towards a hybrid ecosystem of blended learning within university contexts. In CEUR Workshop Proceedings (Vol. 2817). 
McGibbon C, Sexton A, Gryfe P, Dutta T, Jayaraman A, Deems-Dluhy S, Novak A, Fabara E, AdansDester C, Bonato P. Effect of using of a lower-extremity exoskeleton on disability of people with multiple sclerosis. Disabil Rehabil Assist Technol. 2021 Jan 27:1-8. https://doi.org/10.1080/17483107.2021.1874064

Mikkelsen, K., Stojanovska, L., Polenakovic, M., Bosevski, M., \& Apostolopoulos, V. (2017). Exercise and mental health. Maturitas, 106, 48-56. https://doi.org/10.1016/j.maturitas.2017.09.003

Moseley, R. L., Shtyrov, Y., Mohr, B., Lombardo, M. V., Baron-Cohen, S., \& Pulvermüller, F. (2015). Lost for emotion words: what motor and limbic brain activity reveals about autism and semantic theory. Neurolmage. https://doi.org/10.1016/i.neuroimage.2014.09.046

Non-ambulatory people with intellectual disabilities practice functional arm, leg or head responses via a smartphone-based program. J Dev Phys Disabi. (2019) 631:251-65. https://doi.org/10.1007/s10882018-9636-7

Pulay M. Á. (2015). Eye-tracking and EMG supported 3D Virtual Reality - an integrated tool for perceptual and motor development of children with severe physical disabilities: a research concept. Studies in health technology and informatics, 217, 840-846.

Rogers, J. M., Duckworth, J., Middleton, S., Steenbergen, B., \& Wilson, P. H. (2019). Elements virtual rehabilitation improves motor, cognitive, and functional outcomes in adult stroke: evidence from a randomized controlled pilot study. Journal of neuroengineering and rehabilitation. https://doi.org/10.1186/s12984-019-0531-y

Role of Dopamine. Neuropsychopharmacology: official publication of the American College of Neuropsychopharmacology.

Rosenfeld, J. V., \& Wong, Y. T. (2017). Neurobionics and the brain-computer interface: current applications and future horizons. The Medical journal of Australia, 206(8), 363-368. https://doi.org/10.5694/mja16.01011

Schmahmann JD. (2019) The cerebellum and cognition. Neurosci Lett. https://doi.org/10.1016/j.neulet.2018.07.005

Taherian, S., Selitskiy, D., Pau, J., Davies, T. C., \& Owens, R. G. (2016). Training to use a commercial brain-computer interface as access technology: a case study. Disability and rehabilitation. Assistive technology, 11(4), 345-350.

Toto, G. A., \& Limone, P. (2020, September). New Perspectives for Using the Model of the Use and Acceptance of Technology in Smart Teaching. In International Workshop on Higher Education Learning Methodologies and Technologies Online (pp. 115-125). Springer, Cham. https://doi.org/10.1007/978-3-030-67435-9_9

Toto, G.A., \& Limone, P. (2021) From Resistance to Digital Technologies in the Context of the Reaction to Distance Learning in the School Context during COVID-19. Educ. Sci., 11, 163. https://doi.org/10.3390/educsci11040163

Varker, Tracey \& Forbes, David \& Dell, Lisa \& Weston, Adele \& Merlin, Tracy \& Hodson, Stephanie \& O'Donnell, Meaghan. (2015). Rapid evidence assessment: Increasing the transparency of an emerging methodology. Journal of Evaluation in Clinical Practice. https://doi.org/10.1111/jep.12405

Verrusio, W., Renzi, A., Cecchetti, F., Gaj, F., Coi, M., Ripani, M., \& Cacciafesta, M. (2018). The Effect of a Physical Training with the Use of an Exoskeleton on Depression Levels in Institutionalized Elderly Patients: A Pilot Study. The journal of nutrition, health \& aging, 22(8), 934-937. https://doi.org/10.1007/s12603-018-1044-2

Wei, W. (2018). Virtual reality enhanced robotic systems for disability rehabilitation. Virtual and augmented reality: Concepts, methodologies, tools, and applications (pp. 1267-1287). https://doi.org/10.4018/978-1-5225-5469-1.ch061 
Yamauchi, Y., Aoki, S., Koike, J., Hanzawa, N., \& Hashimoto, K. (2019). Motor and cognitive development of children with Down syndrome: The effect of acquisition of walking skills on their cognitive and language abilities. Brain \& development. https://doi.org/10.1016/j.braindev.2018.11.008

Yazıcı, M., Livanelioğlu, A., Gücüyener, K., Tekin, L., Sümer, E., \& Yakut, Y. (2019). Effects of robotic rehabilitation on walking and balance in pediatric patients with hemiparetic cerebral palsy. https://doi.org/10.1016/..gaitpost.2019.03.017 